\title{
A voz do feminino marcado em "Eu e Jimmy", De Clarice LISPECTOR: REFLEXÕES SOBRE GÊNERO E PODER
}

Lucas dos Santos Passos*

LUCIANA BORGES**

RESUMO

Este artigo analisa os conflitos marcados pela assimetria de gênero no conto "Eu e Jimmy", de Clarice Lispector. Para traçar algumas reflexões sobre a (i)materialidade do texto, os ditos e não ditos e os discursos que partem e circulam no conto, no que diz respeito às relações de gênero, partimos do marco binário e oposicional masculino/feminino e da experiência familiar de uma mulher que, desde pequena, assistiu à mãe seguindo as ideias de um pai rígido e imperioso. Uma vez tendo aprendido a supremacia masculina, essa mulher tornou-se uma seguidora cega das ideias de seus namorados e dos homens em geral.

Palavras-chave: Clarice Lispector, relações de gênero, supremacia masculina.

El "yo" es producido a través del poder, aunque no del efecto deterministico del poder. El poder descansa en un mecanismo de reproducción que puede descontrolarse y de hecho se descontrola, que deshace las estrategias de acción del poder y reproduce nuevos e incluso subversivos efectos.

Judith ButLer (2009)

REFLEXÕES INICIAIS: O TEXTO LITERÁRIO E AS QUESTÕES DE GÊNERO

Relacionamento, teorias filosóficas, cabotinismo, evolução da mulher para o animal, abandono como causa da "evolução" e ao mesmo tempo como um paradoxo das relações de gênero: são essas algumas

* Universidade Federal de Goiás, Catalão, Goiás, Brasil.

E-mail: lucassantospassos@gmail.com

** Universidade Federal de Goiás, Catalão, Goiás, Brasil.

E-mail: borgeslucianab@gmail.com 
tramas (leia-se: discursos) que emergem do conto "Eu e Jimmy", da escritora Clarice Lispector, conto pouco conhecido e até bem pouco tempo, de difícil acesso. ${ }^{1}$ No entanto, é entre algumas páginas específicas de Outros escritos, organizado por Teresa Montero e Lícia Manzo, que o conto chega até nós. A própria coletânea foi organizada justamente na empreitada de trazer à luz textos de Clarice que não haviam saído do "fundo da gaveta", por assim dizer, ou outros que saíram, mas encontravam-se dispersos em acervos de dispendiosa localização ou em edições esgotadas. Podemos dizer que o conto mal chega até nós e provoca-nos: é um acinte, texto de fruição. ${ }^{2}$

Ele não só nos oferece a possibilidade (ele mesmo) de fazê-lo reclamar seu lugar na fortuna crítica da autora, torná-lo visível no signo dominante da obra de "Clarice Lispector", reapropriar-se da ilusão estética ou da sociologia do olhar estético, mas (e o que é nossa proposta neste trabalho) oferecer uma leitura crítica, a partir dos estudos de gênero, dos rizomas. Isso porque, como nos diria Gilles Deleuze e Félix Guattari (1995), a obra é um sistema de rizomas e não um sistema Árvore ou Raiz, com sua unidade inaugural, que fixa um ponto, uma ordem, mas é formada pelo sistema de conexão e de heterogeneidade, postulando que qualquer ponto do rizoma pode ser ligado a outro. Também dos fios de malha, no sentido derridiano, compreende-se o texto como não formado pelo centro metafísico, mas pela própria estruturalidade dinâmica que possibilita a polissemia (SAnTiago, 1976). Enfim, o texto emerge dos discursos circulantes, ocultos, dos personagens... Todos eles sempre irreduzíveis ao sentido, à captura plena.

$\mathrm{Na}$ verdade, Roland Barthes (1988) já nós alertava quanto a essa interpretação plural e impossível do Texto, ele aniquilou a intenção do autor, matou-o, deixando as análises literárias um tanto mais difíceis. Para ele, nada mais fala no texto do que a própria linguagem mesma, já que a escritura destrona o sujeito, sua voz, a origem, ela aniquila o autor, e há de se entender que o autor é um personagem moderno produzido por nosso vislumbre à "pessoa física". Sendo assim, não existiria o sentido único do texto, aquilo que o Autor (se assemelhando a Deus e à voz performativa divina intencionou em dizer) usou em uma escritura fechada em torno de um significado último, ao contrário, é a leitura o verdadeiro lugar da escritura, da significação múltipla do texto, 
fios que nos convidam a deslindá-la e não decifrá-la, já que não existe o fundo do texto, não existe Deus.

Em "Eu e Jimmy", através das lembranças da narradora (e/ou protagonista) inominada, somos apreendidos pelo relacionamento conflituoso entre ela e seu ex-namorado, Jimmy, de cabelos castanhos e despenteados, crânio alongado de "rebelde nato", cabeça erguida, nariz espetado no ar... Suas ideias, as ideias de Jimmy, ideias que recaíam sobre a narradora, guiam-na e a distanciam de seu padrão, aproximando-a de um animal, nos dizeres de Jimmy. Ela nada poderia fazer, porque, como uma mulher, uma construção social e histórica, um sujeito das normas de gênero que se passa como um ser essencial, como presença, tinha internalizado essas normas através da própria experiência familiar: papai, mamãe - a sagrada família. Do espaço privado ao público, ampliando territórios, ela ainda constata que, num nível global, as ideias dos homens também pesam sobre as ideias das mulheres, o mundo é sempre o mundo dos homens.

É também, tornando-se animal, através dos ensinamentos filosóficos de Jimmy, que a protagonista nos oferece outra situação para (re)pensar as relações de gênero, aliás, uma situação um tanto quanto paradoxal: o animal-mulher se abre também para outros homens e isso afeta o namorado, justamente por ele ser um homem, igualmente uma construção histórico-social, fruto da matriz de gênero, ocupando lugar dominante, honrado e respeitável.

Nesse sentido, nós nos propomos, através das lembranças, dos rastros, dos ditos e não ditos da narradora, realizar reflexões sobre o mundo centrado na figura do bio-homem-macho, suas ideias como as ideias dominantes, como sua figura, estão para cultura e, nesse caso específico, para a filosofia e a mulher para a natureza (animal). Além disso, através do paradoxo que circula em "Eu e Jimmy", encerra-se (na verdade, nunca se encerra) o trabalho refletindo sobre o agenciamento de gênero, como as normas podem (e realmente) falhar e como o próprio poder se abre para a sua modificação. Para tanto, amparou-se em leituras do pensamento filosófico feminista como o fundamental de Simone de Beauvoir (1980a; 1980b) e Monique Wittig (2006); a perspectiva antropológica de Pierre Bourdieu (2010); o olhar desconstrucionista de Judith Butler (2008a; 2008b; 2009) e da acadêmica australiana Elizabeth Grosz (2000), entre outros. 
Segundo a protagonista, Jimmy a pegava pelo braço como íntimo e isso a perturbava, mas ela repreendia essa perturbação, porque, nesse tempo, já estava imbuída pelas ideias de Jimmy e seu sorriso claro, mas não gostava dele, procurava apenas uma desculpa para esse ato, para seguir suas ideias, já que

desde pequena tinha visto e sentido a predominância das ideias dos homens sobre a das mulheres. Mamãe antes de casar, segundo tia Emília, era um foguete, uma ruiva tempestuosa, com pensamentos próprios sobre liberdade e igualdade das mulheres. Mas veio papai, muito sério e alto, com pensamentos próprios também, sobre... liberdade e igualdade das mulheres. (Lispector, 2005, p. 17)

É interessante notar como a narradora faz uma breve historicização mostrando o porquê de ela seguir as ideias de Jimmy: ela, desde pequena, isto é, desde a infância, tinha visto esse fato, a certeza de que as ideias dos homens prevalecem sobre as das mulheres, uma vez que a própria relação entre seu pai e sua mãe (família) já lhe transmitira (uma questão de geração) essa supremacia do macho. Essa observação é certamente uma questão das relações assimétricas de gênero que, lendo Simone de Beauvoir (1980a; 1980b), compreendemos que o gênero é uma construção social e que, portanto, a masculinidade do macho ou a feminilidade da fêmea já começam a ser construídas desde a infância como acontece com a nossa personagem.

Em primeiro lugar, Beauvoir (1980a) afirma, contra os argumentos e contra as próprias condições sociais que relegam à mulher uma condição inferior, incapacitada, subalterna, subserviente etc., que a fêmea humana não nasce mulher (ser), mas sempre sob uma compulsão obrigatória a fazê-lo (ter), torna-se, portanto, mulher. Partindo do dinamismo hegeliano entre ser/ter, a autora nos esclarece que ser inferior é ter sido tornado inferior, ter sido produzido tal como se manifesta, já que é pelo $U m$ se definindo como $U m$ que se define o Outro, nenhum outro sujeito se coloca como inessencial, mas sempre sob uma égide do poder. Dessa forma, a inferioridade que é relegada socialmente à mulher só pode ser explicada à medida que se entende o gênero como uma construção sob o sexo que o designa, uma inscrição 
de significados culturais que se inscrevem sob o corpo e autorregulam a condição da pessoa, encerrando a mulher num estado particular, marcado, enquanto o homem tem sempre o status universal, de Sujeito, o Absoluto, o Um.

Também Monique Wittig (2006) afirma que o sexo é uma marca exclusiva da mulher; ela não pode ser tomada por fora dessa marca e, por isso, é relativizada e particularizada: ser sexuado é sempre ser mulher e essa sexualização violenta torna-a invisível enquanto ser social, ela é apenas ser sexual. Assim, o sexo teria se tornado o suplemento (supplément), no sentido derridiano, das mulheres, sem que possamos responder "Quem vem antes de quem: a mulher ou a categoria do'sexo'?”, porque ser mulher é ser sexuado, ou seja, o sexo tomou a categoria da pessoa e nós não temos acesso a ela a não ser por meio dessa marca; seu espírito, seu corpo, seus atos e gestos se converteram em sexo. Consequentemente, só há também um gênero para a autora, $o$ feminino, porque o masculino não é um gênero, mas o geral.

Beauvoir (1980b) nos alerta que, desde a infância, a feminilidade da menina vai se constituindo por meio de vários processos: o desmame, os afazeres domésticos, as brincadeiras, os brinquedos e, ao que mais nos interessa, através da experiência, pois se voltamos ao excerto é a experiência da infância que nos é relatada. Segundo a autora, a experiência mostra à menina que a autoridade do pai é mais soberana, embora não vivenciada fortemente, já que quem reina em casa (espaço privado) é a mãe. Tudo é colocado à vontade do pai e em seu nome exige-se, recompensa-se ou pune-se. Nesse contexto imaginado, mas não irreal, essa menina também passa a compreender como a vida desse pai é cercada de prestígio e como as horas que ele passa em casa são mistificadas: seus objetos e suas manias são sagrados. No final das contas, ela entenderá que é o pai quem alimenta a família, é o ser responsável, ele é Deus, o chefe, trabalhando fora, traz dinheiro e comida para casa, ligando-os com o resto do mundo - espaço público. Ela entenderá que o mundo sempre pertenceu aos machos, o que de fato acontece com a narradora de "Eu e Jimmy", que aprende essa "realidade" pela família, primeira instituição de que faz parte.

Há uma reflexão valiosa aqui: o gênero e a geração se articulam juntos, reproduzindo na personagem a condição feminina enquanto ser inferior, fazendo-a seguir as ideias de Jimmy. Assim, há de se considerar 
que não basta tomar a categoria do gênero de um lado e da geração de outro, nesse caso, a análise tem de perpassar a junção mesma dessas duas categorias fundantes da vida do ser social. De fato, como bem esclarece Alda Motta (2005), entre as dimensões históricas e cotidianas mais básicas da vida social, está a categoria da geração, que se articula com as categorias de gênero, classe e raça, categorias relacionais ou de experiência, que expressam diferenças, oposições, conflitos e/ou identificações, alianças e hierarquias provisórias entre os indivíduos ou grupos.

Das relações que partem da geração e do gênero, entende-se que a diferenciação social entre homens e mulheres constrói diferentes representações geracionais ou, em relação à faixa etária, normatizando hierarquias internas, formas de viver dimensões básicas das relações sociais. Dessa forma, a geração, categoria complexa de análise, segundo Motta (2005, p. 133), refere-se a "uma dimensão fundante da vida social, em articulação inextrincável com as já referidas categorias relacionais de semelhante magnitude, projeta-se mais especificamente que aquelas, na dimensão temporal, tempo simultaneamente 'natural' e social, segundo o qual faz e refaz seus sentidos".

No conto, a narradora não só tinha visto e sentido a supremacia das ideias dos homens sobre as das mulheres, como também internalizado essa organização (tanto é que ela segue as ideias de Jimmy, porque dada essa internalização, o que ela poderia fazer?) e, ao que fica claro, especialmente pela experiência da infância promovida pelos dinamismos familiares. A experiência adquirida pela organização assimétrica entre pai e mãe, homem e mulher, com quem a personagem mantém grau de filiação, claramente, acaba por produzi-la também como a mulher que cede suas ideais às ideias dos homens. A categoria da geração, categoria fundante da vida social, como vimos, articula-se então de forma imprescindível à família, justamente por ser a primeira instituição a que o indivíduo faz parte e pela qual se internaliza entre outras normas, as normas de gênero, isto é, o regulamento obrigatório pelo qual torna-se mulher ou torna-se homem.

O trabalho de Motta (2005) ainda faz eco aos pressupostos de Pierre Bourdieu (2010) dizendo que nós somos sempre o jovem ou o velho de alguém. De fato, em "Eu e Jimmy", a protagonista é a "jovem" de seus pais, o que não significa apenas uma questão da idade (ser "jovem", "velho"), mas como através da geração, há um "eu”, 
devidamente posicionado ("pai", "mãe") pelo dinamismo familiar, atrás e sob a posse desse "jovem", que faz parte de sua construção como homem ou mulher.

Entender a produção e reprodução da condição da pessoa parece uma tarefa desde Marx e Engels (1998), pois consideravam que, no renovar diário humano, o homem também renova sua própria vida, ele cria outros homens, procria: a relação entre homem e mulher, entre pais e filhos, a família. Para o pensamento materialista, há uma produção e reprodução tanto da vida material, isto é, dos meios materiais de existência (alimentos, roupas etc.) quanto dos próprios homens (a propagação da espécie), o que é essencial à própria vida. Nesse sentido, não podemos nos desviar do entendimento de que a sagrada família tanto (re)produz a espécie quanto a própria pessoa, as relações entre pais e filhos, entre homens e mulheres e todas as outras, o duplo movimento da produção da vida material, do qual não podemos descartar as normas de gênero, a fabricação do Um masculino e do Outro feminino.

Ainda, se nos dirigimos ao pensamento foucaultiano, compreendemos que a família é ela própria uma instituição consolidada pelas normas do gênero, formada pela constituição de casais legítimos caracterizados pela obrigatoriedade conjugal, heterossexual e monogâmica, além de que a família é o lugar da pacificação e domesticação do sexo. Assim, Michel Foucault (1999) nos esclarece que essa família do XIX confisca a sexualidade, absorve-a na função exclusiva da reprodução, importa-a para dentro da casa, especificamente para o quarto do casal, detendo e reproduzindo os saberes sobre o "sexo". Portanto, existem alguns lugares, momentos e algumas relações sociais, dentre os quais está a família e, claro, a categoria da geração, que funcionam como dispositivos centrados no próprio poder, eles próprios regulam o discurso sobre o "sexo", mantendo e/ou impondo o que é necessário para a nossa sociedade capitalista.

Nesse sentido, um discurso oculto, em "Eu e Jimmy", não é o de que a família, como instituição, é sempre um dispositivo da construção histórica do indivíduo? Nós não estamos aqui no campo que Teresa de Lauretis (1994) chama de tecnologia do gênero? A própria autora deixa clara a sua apropriação de Foucault, para quem existe uma tecnologia política que produz o gênero nos corpos, comportamentos e nas relações sociais, nada existindo a priori, mas ela também nos diz que a sua aná- 
lise sobre a tecnologia do gênero leva em conta as diferenciações entre os sujeitos masculinos e femininos, que a teoria foucaultiana deixa de lado. Nesse sentido, a autora considera que o gênero seja representação (que é ao mesmo tempo sua construção) e autorrepresentação, pois o sujeito é constituído por um poder anterior a ele mesmo, mas também um produtor de signos no interior desse poder e, portanto, produto de uma complexa tecnologia política que significa os corpos.

De outro lado, a filósofa Beatriz Preciado (2013), que também segue o mesmo pensamento de Lauretis, nos evidencia no texto "Qui défend l'enfant queer?", como resposta ao atual debate sobre a preservação conservadora da família e, em especial, contra os propósitos heterocratas da "Manifestação para todos", ${ }^{3}$ que a criança é o ponto de partida para a normalização do adulto, um artefato biopolítico que não tem voz, que não pode se rebelar politicamente, construído pela ordem doméstica heterossexual. Do mesmo modo, parece consenso na crítica feminista atual que, para se pensar as mulheres e seu lugar no mundo, é necessário pensar nas meninas. Diante dos discursos heterocentrados dos manifestantes em Paris, que estavam contra a legalização do casamento entre pessoas do mesmo sexo e a adoção de crianças por eles, os de Frigide Barjot se destacaram, posto que a autora faz uma crítica severa. Ela afirma que a polícia do gênero vigia os berços, os corpos meigos, através dos pais, reproduzindo a normativa heterossexual da masculinidade e feminilidade. Isso significa que as crianças, corpos dóceis de antemão, tanto no próprio sentido biopsíquico quanto no sentido de que elas não têm voz na nossa sociedade, são, pela família, trabalhadas e moldadas pelas normas de gênero, já que "pai" e "mãe", antes de qualquer coisa, são categorias de poder, tecnologias do gênero. Para a criança queer que ela era, as normas de gênero haviam roubado seus pais dela, impedindo-a de ter um pai e uma mãe, amor e cuidados. Nesse sentido, Preciado (2013) afirma que seu pai foi minimizado ao papel de representante soberano das normas da lei de gênero e sua mãe, privada de tudo o que ia além da sua função de útero, de reprodutora da norma sexual.

Essa autora defende claramente que as pessoas são produzidas e reproduzidas dentro das normas sexuais e de gênero e que a família, nesse processo, é a principal matriz por conservar a mesma estrutura de marco binário e oposicional - a heterossexualidade/cissexualidade 
-, reduzindo seus pais aos "velhos" que estão antes dela, que decidem e modelam a vida de uma criatura sem voz, que tem de ser, desde o início, heterossexual e terminar sua vida no mesmo marco compulsório do gênero. Na verdade, as categorias parentais podem sugerir amor e cuidado, quando oferecem apenas as próprias normas de gênero, a lei para a autora, para a protagonista de "Eu e Jimmy", de que devem ser reduzidas apenas as funções reprodutivas, sendo o significado construído historicamente para a feminilidade.

REFLEXÕES SOBRE AS DICOTOMIAS: A PROTAGONISTA ESTÁ PARA A DESRAZÃo?

A voz da narradora segue no texto, nos dizendo que

hoje mamãe cose e borda e canta no piano e faz bolinhos aos sábados, tudo pontualmente e com alegria. Tem ideias próprias, ainda, mas se resumem numa: a mulher deve sempre seguir o marido, como a parte acessória segue a essencial. (LISPECTOR, 2005, p. 17)

Aqui, pelo fato de as ideias da mãe da narradora se resumirem na ideia central de seguir o marido, parece muito evidente a análise marxista de que as ideias das classes dominantes são as ideias dominantes, em todas as épocas, ${ }^{4}$ são elas que constroem e reconstroem o mundo à sua própria consciência e essa consciência é dominante em todos os sentidos. Lembremos que Wittig (2006) nos aponta que o pensamento dominante das relações de gênero distribui para as mulheres um conjunto de tarefas, de aprioris nos dizeres da autora, que existe de antemão um "aí" dos sexos, a ideologia da diferença sexual da qual não se pode escapar. De fato, percebe-se no conto os movimentos no espaço privado, as tarefas do lar: coser, bordar, cantar ao piano, ter filhos e fazer bolinhos (aos sábados), movimentos que a ideologia da diferença sexual exige das mulheres e, é claro, movimentos acompanhados de pontualidade e alegria. Sobre isso, em A dominação masculina, o sociólogo francês Pierre Bourdieu (2010) afirma que, das mulheres, "se espera que sejam 'femininas', isto é, sorridentes, simpáticas, atenciosas, submissas, discretas, contidas ou até mesmo apagadas” (p. 82).

Como Wittig (2006) apontara, a categoria do sexo enquanto categoria de dominação não pode ser outra senão social, já que não 
existe dominação de outra ordem e obviamente, nesse caso, exercida pelos homens sobre as mulheres. Assim, desconstrói-se a naturalidade da opressão e a premissa básica de que o sexo existe antes de qualquer sociedade, oferecendo outro regime discursivo, no qual, segundo a autora, a categoria do sexo é uma categoria política que funda a sociedade heterossexual, as relações construídas, oposicionais e binárias entre homens e mulheres, a fabricação, isto é, a heterossexualização das mulheres com suas funções domésticas e reprodutivas, a exploração que funda ela própria a economia heterossexual.

Essa economia está colocada no conto, as posições que homens e mulheres ocupam dentro da lógica heterossexual, sobretudo quando observamos a questão das ideias dominantes, as ideias que a mãe da narradora segue, assim como ela própria segue as de Jimmy, porque, no marco da política heterossexual e, portanto, da política das normas sexuais e de gênero, a parte acessória (a mulher) segue o essencial (o homem). Essa conclusão formulada pela narradora, a partir de suas aulas de Direito, é extremamente cara, especialmente se levamos em conta a própria opressão das mulheres, sua constituição como Outro. Aqui, não poderíamos nos esquecer de um trecho de $O$ segundo sexo:

[a mulher] não é senão o que o homem decide que seja, daí dizer-se o 'sexo' para dizer que ela se apresenta diante do macho como um ser sexuado: para ele, a fêmea é sexo, logo ela o é absolutamente. A mulher determina-se e diferencia-se em relação ao homem e não este em relação a ela; a fêmea é o inessencial perante o essencial. O homem é o Sujeito, o Absoluto; ela é o Outro. (Beauvorr, 1980a, p. 10)

Masculino/feminino, Sujeito/Outro, superior/inferior, pai/mãe, público/privado, essencial/inessencial: está claro como as mulheres estão marcadas nessas relações assimétricas, especialmente se escutamos a voz do texto. Laclau, citado por Stuart Hall (2011), nos esclarece que a identidade se afirma sempre por meio de uma repressão daquilo que a ameaça, excluindo violentamente o Outro e estabelecendo uma hierarquia entre os dois polos resultantes. Assim, "mulher" é um termo marcado em relação ao "homem", termo não marcado; ela é a exclusão do campo da supremacia masculina, sua différance, no sentido derridiano. Os homens, em posições laterais do exterior, oficial, público, direito, seco, alto, descontínuo, realizam os trabalhos dignos de valor, 
enquanto as mulheres, situadas em posições lateralmente negativas do úmido, baixo, curvo, são relegadas aos trabalhos domésticos, trabalhos que se realizam no espaço privado, de forma escondida e até mesmo invisíveis e vergonhosos (Bourdieu, 2010).

No conto, percebemos uma oposição bastante peculiar e que pode ser pensada nessa mesma lógica: cultura/natureza, mente/corpo. A narradora deixa claro que seguia as ideias de Jimmy pela experiência, para tornar-se um tipo padrão, que era animal. Jimmy é o tutor desse processo, o ser filosófico, homem, que age sobre a namorada, trabalhando-a. Assim, Jimmy está para a cultura e para a mente e a narradora, para a natureza, consequentemente, para o corpo, termos que continuam homólogos à posição hierárquica entre o masculino e o feminino. Isso nos remete ao artigo "Corpos reconfigurados", de Elizabeth Grosz (2000), em que a autora nos traça uma análise fundamental para entender como esses binarismos funcionaram dentro do campo filosófico e dentro do próprio feminismo.

Grosz (2000) considera a série correlativa e associativa entre mente/corpo com homem/mulher, razão/paixão, sensatez/sensibilidade, fora/dentro, ser/outro, profundidade/superfície e outros, tendo a filosofia se relacionado com o homem, porque ela se preocupou desde o início com questões de ordem racional, ideias, conceitos, ou seja, com as questões da mente, excluindo-se, portanto, as mulheres porque entendia-se que a desrazão estava relacionada ao corpo. Nesse sentido, traçando uma historicização dessa dualidade, a autora afirma que, desde Platão, o corpo é considerado como um locus perigoso para a razão, já que, trazida pelos sacerdotes órficos, a palavra corpo significava um ser espiritual aprisionado, logo, uma imperfeição da Ideia.

Em Aristóteles, como nos esclarece Grosz (2000), inaugura-se a dualidade matéria/forma, acreditando-se que a mulher oferecia na maternidade uma matéria sem forma (útero), enquanto o pai dava o contorno, a definição, a forma, aquilo que o útero não era capaz de fornecer. Reconfigurada posteriormente pela tradição cristã, a mente representa o que é imortal e o corpo o que é mortal, pecaminoso. Davis (1997) afirma ainda que fisiologistas apropriaram-se dessa ideia aristotélica, propagando que toda constituição psíquica da mulher se concentra no útero, reduzindo-a ao corpo e negando a sua racionalidade e autonomia; Soranos, por exemplo, estabeleceu que a histeria, vindo 
etimologicamente da palavra grega hystera (útero), nada mais era do que o produto do processo migratório do útero, matéria desregrada, para outras partes do corpo feminino. Vale lembrar que Judith Butler (2008a) também nos diz que uma explicação para a associação clássica entre feminidade e materialidade pode ser a série de etimologias que relacionam a matéria com mater e matriz, ou seja, com o útero e, portanto, com a reprodução.

Depois, Descartes distinguiu dois tipos de substâncias: a res cogitans (a mente) e a res extensa (o corpo). Para ele, o corpo pertencia à natureza, regido pelas leis causais e leis da natureza; já a mente, a alma, não pertencia a esse mundo da matéria; portanto, seria o pré-requisito para a fundação de uma ciência do entendimento da matéria mesma, da racionalidade e objetividade (Grosz, 2000).

Nós temos aqui a tradição filosófica, como nos disse Butler (2008b), iniciada em Platão, depois prolongada com Descartes, Husserl e Sartre, que partindo da distinção ontológica entre corpo e mente mantém relações de subordinação e hierarquia de ordem política e psíquica entre os termos. Estamos, assim, no campo problemático da dicotomia, conforme Grosz (2000), pelo qual se funda a filosofia e do qual se reapropria o próprio feminismo. Para a autora, o problema está não na dominação do par binário, mas no estabelecimento do $U m$, que não admite nenhum Outro, já que a alteridade se funda nessa criação de uma barreira em torno de si, produzindo o binário. Na perspectiva da autora, os termos são hierarquizados pelo pensamento dicotômico, um polarizado positivamente e o outro negativamente: o um expulsa seu outro, sua negação, recusa, criando uma identidade para si mesmo; a mente expulsa o corpo como seu outro, termo subordinado e desprivilegiado pela Filosofia. Desse modo,

dada a relação da mente com a masculinidade e do corpo com a feminilidade e dada a autocompreensão da filosofia como um empreendimento conceitual, segue-se que mulheres e feminilidade são problematizadas como sujeitos filosóficos cognoscentes e objetos epistêmicos cognoscíveis. A Mulher (com maiúscula e no singular) permanece o eterno enigma da filosofica, seu objeto misterioso e inescrutável - o que pode ser um produto do estatuto misterioso e altamente contido em particular, na construção da filosofia como um modo de conhecimento. (Grosz, 2000, p. 51) 
Ora, a protagonista e seu ex-namorado não seriam a personificação desse excerto? No conto, está claro que Jimmy desempenha uma tutoria filosófica no relacionamento com sua namorada, encaminhando-a para uma aproximação do padrão da mulher, que é a natureza. Desse modo, os personagens representam as séries de oposições homólogas à dicotomia inicial masculino/feminino: natureza/cultura, mente/corpo, razão/desrazão. Jimmy, o homem, é a alegoria do estabelecimento da filosofia como conhecimento puramente conceitual, das ideias, da razão pura, não marcada pelo corpo. Aliás, a filosofia (mente) é a responsável por desvendar esse corpo, termo inferior, que está relacionado à mulher, regido pelas leis físicas e leis da natureza. Esse último movimento também está no texto, pois é Jimmy quem encaminha uma série de aprendizagens filosóficas para a sua namorada, fazendo-a aprender que, quando duas pessoas se gostam, elas não podem fazer mais nada a não ser se amarem e tudo o que se afasta disso é "cabotinismo e espuma".

Retomando Laclau, citado por Hall (2011), percebemos, no conto, o funcionamento do exterior constitutivo pelo qual as identidades são construídas, excluindo-se, nesse campo, de forma lateral ao feminino, no estabelecimento do masculino superior, os termos mente, desrazão, histeria, matéria etc., corpos altamente marcados de frente pelos termos não marcados, que são, dessa forma, masculino, mente, razão etc. $\mathrm{Na}$ verdade, a dicotomia inicial entre homem/mulher, masculino/feminino, está claramente distribuída no interior do texto, seja entre Jimmy e a protagonista ou entre ou pais desta: o masculino é um termo não marcado, a identidade construída positivamente, enquanto a identidade feminina é construída negativamente, à margem do masculino.

REFLEXÕES SOBRE A CONTINGÊNCIA DO GÊNERO: O PARADOXO DE “Eu E JiMMY"

Quanto à protagonista de “Eu e Jimmy”, aluna aplicada em que se haviam produzido efeitos raros, coloca em exame suas aprendizagens, porque, para ela, era necessário fazer exames, e se apaixona por um de seus examinadores, D... (o nome não é revelado), seus olhos eram suaves e profundos; suas mãos, bonitas e morenas e suas ideias, não jimiescas, nos termos hegelianos ouvidos no jardim silencioso e frio à luz do crepúsculo. Sobre isso, podemos acompanhar a protagonista, na prática de sua animalidade, moldada pelos termos hegelianos do 
pensamento filosófico, dizer a Jimmy que o primitivo equilíbrio se rompera, surgindo outro numa outra base e ela não poderia unir os contraditórios, fazendo a síntese hegeliana. A expressão de Jimmy é descrita no trecho abaixo:

Jimmy olhava-me estupidamente e só soube perguntar:

$-\mathrm{E}$ eu?

Irritei-me.

Não sei, respondi, chutando uma pedrinha imaginária e pensando: ora, arranje-se! Nós somos simples animais. (LisPECTOR, 2005, p. 18)

E, em seguida, nós lemos um paradoxo:

Jimmy estava nervoso. Disse-me uma série de desaforos, que eu não passava de uma mulher, inconstante e borboleta como todas. E ameaçou-me: eu ainda me arrependerei dessa mudança súbita. Em vão tentei explicar-me com as suas teorias: eu gostava de alguém e era natural, apenas; que se eu fosse "evoluída" e "pensante" começaria por tornar tudo complicado, aparecendo com conflitos morais, com bobagens da civilização, coisas que os animais desconhecem em absoluto. Falei com uma eloquência adorável, tudo devido à influência dialética do examinador (aí está a ideia de mamãe: a mulher deve seguir... etc.) Jimmy, pálido e desfeito, mandou-me para o diabo a mim e as teorias. Gritei-lhe nervosa, que não eram minhas essas maluquices e que, na verdade, só podiam ter nascido de uma cabeça despenteada e comprida. (LISPECTOR, 2005, p. 18-19)

Ora, por que Jimmy se sentiu assim? Por que, para ele, funcionava esse distanciamento da moralidade, da monogamia, enquanto sua namorada ao colocar em prática sua animalidade acabou o ferindo? Não estava claro que, para Jimmy, não existia nada tão bom quanto a natureza, o amor longe dos conflitos morais e civilizatórios? Ele não concordava com a posição da namorada, mas ele próprio havia ensinado isso a ela, desprezava as ideias dela, porém aquelas eram suas ideias. Aqui, temos um paradoxo, já que as próprias ideias pregadas por Jimmy, na construção da namorada como animal, voltam-se contra ele, dado que a animalidade desconhece a moralidade e a monogamia: Jimmy estava contra isso nela. 
De novo, estamos diante das relações assimétricas de gênero: a protagonista tinha de ser fiel a Jimmy, enquanto ele não era fiel a ela nem aceitava a premissa filosófica hegeliana de que o equilíbrio primitivo entre os dois havia se quebrado e um novo havia se formado, numa outra base, com outra pessoa, embora ainda o estivesse namorando. Parece contundente pensar essa impossibilidade dentro da lógica das normas de gênero, do rebaixamento do feminino, de forma que é exigida da mulher uma fidelidade não recíproca.

Inevitavelmente, não podemos deixar de oferecer um discurso amparado pelos estudos de gênero sobre a materialidade textual do paradoxo em "Eu e Jimmy", sobre a irrupção da protagonista contra seu ex-namorado, direcionada por ele mesmo. De forma irônica, a mesma materialidade atribuída à mulher, o movimento da marca falogocêntrica da Filosofia, o estatuto masculino (mente) da compreensão e da modelação do ser feminino fazem com que a protagonista do conto, ao se afastar do pensante e ocupar o seu lugar na dicotomia de corpo, natureza, fuga, da fidelidade não recíproca estabelecida pelas normas de gênero, subverta em parte sua posição de inferioridade, já que o "animal" desconhece a língua dos humanos, a premissa básica que uma namorada deve honrar, isto é, ser fiel ao namorado enquanto ele não tem essa obrigação, justamente por sua posição como Sujeito, Absoluto.

$\mathrm{Na}$ verdade, o paradoxo parece sugerir que o contrapoder, a subversão do poder, é feito na própria estrutura do poder e não num campo alheio pelo qual se pretende descontruir o poder em questão; em linhas gerais, o poder é revolucionário, o ponto de agência para a sua desconstrução. $\mathrm{Ou}$, ainda, que o poder é formado num campo contingente, furtivo, ou seja, não determinístico e que ele pode (e realmente se faz) desregular, produzindo sua negação, o espaço para a agência do Outro, a desestabilização das relações mesmas. Talvez, essa instabilidade e essa subversão estejam presentes no conto desde o início, como a parte não dita do significante, aquilo que nossos olhos não poderiam captar, mas cuja escritura reclama ela própria: a voz que chega até nós vem de um lugar marcado pelas relações de gênero, do feminino marcado, sem um nome próprio, mas também chega como a própria voz do feminino agenciador, a voz da contingência do poder. Assim, o que marca o conto "Eu e Jimmy" é um duplo gesto, no sentido derridiano da palavra, a inversão e o deslocamento da própria desconstrução (DERRIDA, 2001). 
Dessa forma, os gritos de raiva de Jimmy, sua consideração de que a namorada era como todas as mulheres e todas as mulheres eram inconstantes e borboletas, seu sentimento de que era ela quem havia feito tudo errado, fazendo o que ele explicou se tornar um tempo perdido (e, aliás, segundo o personagem, tudo com ela era tempo perdido) e o insulto "Vai para o inferno" que estão disponíveis na materialidade das páginas finais do conto, são os próprios gritos da instabilidade do gênero, do pânico e da melancolia. A inversão desses discursos, dos quais não podemos nos desviar (e gostaríamos de dizer que o discurso carrega sempre a impossibilidade de sua recusa), reclama a compreensão de que as normas de gênero também governam os corpos dos homens, que eles também são uma construção e não um sujeito universal, seu status superior é construído. É claro, Bourdieu (2010, p. 63) já nos dizia que "os homens também estão prisioneiros e, sem aperceberem, vítimas, da representação dominante".

Aqui, é plenamente justificável concordar com Butler (2008b), por afirmar que o gênero "é a estilização repetida do corpo, um conjunto de atos repetidos no interior de uma estrutura reguladora altamente rígida, a qual se cristaliza no tempo para produzir a aparência de uma substância, de uma classe natural de ser" (p. 59). Nesse contexto, o gênero não é uma substância, uma essência da "pessoa", mas os efeitos do poder estilizados nesse corpo que criam a própria aparência de substância e essência, porque em nenhum lugar nossos olhos podem captar a historicidade desse processo: diz-se "eu sou um homem" ou "eu sou uma mulher" como verdades carnais, verdades do próprio corpo.

Nessa altura, não podemos deixar de compreender a noção de performatividade de gênero, visto que, para Butler (2008a; 2008b), seguindo a noção de performatividade em Austin e Derrida, o gênero se mostra performativo, porque sempre denota a reiteração das normas de gênero e seu tempo presente, ou seja, cristalizado, dissimula as condições reiterativas, criando os efeitos de um "eu" com gênero desde o início. Não é preciso ir muito longe para perceber, por exemplo, como a identidade de homem e mulher evoca o performativo, a atribuição do gênero recoloca sobre a pessoa as normas que a tornam inteligível dentro da hegemonia heterossexual.

A grande observação da autora está em pensar como algumas identidades, por exemplo, a da drag queen ou da travesti, brincam com 
a ordem sexo/gênero que postulam que do macho humano decorre o gênero masculino e da fêmea humana, o gênero feminino, porque, ao contrário, elas subvertem essa ordem, já que o gênero dessas identidades é denotado inversamente em relação ao seu sexo. Na verdade, tanto a drag quanto a travesti parecem mostrar que o gênero é uma paródia compulsória de que não podemos nos desviar de fazê-lo e, é claro, a noção de paródia, conforme Butler (2008b), "não presume a existência de um original que essas identidades parodísticas imitem. Aliás, a paródia que se faz é da própria ideia de um original” (p. 197), uma imitação que nunca retorna a um original, porque esse não existe.

A autora também afirma que o gênero requer uma performance reiterativa, "realizada com o objetivo estratégico de manter o gênero em sua estrutura binária - um objetivo que não pode ser atribuído a um sujeito, devendo, em vez disso, ser compreendido como fundador e consolidador do sujeito" Butler (2008b, p. 200), não um ato teatral, mas um regulamento que se inscreve em nossos corpos antes mesmo do nascimento.

Pensar a performatividade do gênero é pensar as normas que recaem sobre os corpos (e, é claro, produzindo, antes de qualquer coisa, os próprios corpos) masculino e feminino, mantendo-os no marco binário e oposicional da hegemonia heterossexual, inclusive, a conduta moral que exige fidelidade da mulher (e as punições de sua infidelidade) e possibilita ao homem escapar dessa pretensão. Claramente, a fidelidade é uma restrição atribuída à sexualidade feminina e não à masculina. $\mathrm{Na}$ verdade, pensando desde a perspectiva dos estudos de gênero, entendemos, como Beauvoir (1980a), que a mulher é produzida historicamente como propriedade privada do homem (e a própria propriedade privada só acontece mediante essa reificação do feminino), não elevada à condição de dignidade humana: ela é trocada de pai para marido e este a quer virgem e fiel, fato que não é recíproco da parte dele.

Também como Sarti (1989), para quem o código moral sexual é uma premissa para a existência feminina, já que o campo sexual é construído como referência moral para a mulher, e esta marca é o que diferencia as próprias mulheres no imaginário social: santa/prostituta, moça de família/mulher de vida fácil etc. Pelo que a autora expõe, entende-se que a própria organização do espaço público e do privado se relaciona com a restrição da fidelidade feminina. Na relação conjugal, 
exige-se da mulher que se mantenha no espaço privado, a casa; já a rua, espaço com conotação, pode sugerir à mulher uma sexualidade fora da relação, uma vez que o feminino associado lateralmente ao corpo e ao descontrole do corpo pode também não regular sua sexualidade, mantendo relações com outros homens. O grande problema aqui, segundo Sarti (1989), é que a infidelidade feminina pode deixar marcas (a gravidez, por exemplo), a masculina não; por esse motivo, ignora-se a infidelidade do homem, já que a mulher é vista como ser moral dentro da família e responsável pela moralidade, enquanto o homem como ser produtivo.

Mas, é claro, e o que está claro no conto, a norma do gênero não pode ser plenamente internalizada, uma vez que o "interno", segundo Butler (2008b), é uma significação de superfície e o sujeito "não é determinado pelas regras pelas quais é gerado, porque a significação não é um ato fundador, mas antes um processo regulado de repetição que tanto oculta quanto impõe suas regras" (p. 209; grifos no original), sobretudo pela produção de efeitos substancializantes. Ou, ainda, conforme Butler (2009), a norma de gênero não é nem determinística nem elegida, mas performativa, descansando num mecanismo de reprodução que se descontrola, desfazendo a ação do poder e reproduzindo efeitos subversivos.

Nessa ruptura e sutura do poder, parece bastante claro que o discurso da narradora se coloca em outro terreno que não pode ser compreendido no regime anterior, o movimento da própria desconstrução derridiana, já que a exposição da contingência do gênero revela a contingência dos próprios efeitos substancializantes, da própria essência, rasurando as dicotomias violentas, indo além delas. Quando a narradora faz uso da própria matéria para a qual é direcionada e essa apropriação se mostra subversiva, escapando à regulação sólida das normas de gênero, revela-se a instabilidade dessas normas, sua contingência.

REFLEXÕES INACABADAS OU NUNCA CONCLUSIVAS: AINDA O TEXTO, AINDA O GÊNERO

Iniciamos este texto com o objetivo de traçar um campo discursivo que se construía na e para a leitura de "Eu e Jimmy", de Clarice Lispector, conto que nos oferece a voz de uma narradora falando 
de um lugar marcado pelas relações assimétricas de gênero, a partir das lembranças de seu conflituoso relacionamento com o ex-namorado, Jimmy. Nesse sentido, dispensamos a intenção do autor, rompendo radicalmente a aliança do autor com o conteúdo de seu discurso, a significação fundacional, afastando a premissa teológica de decifrar a voz do Autor (Deus), mas considerando que é a linguagem mesmo que fala e que a enunciação é sempre um processo a ser deslindado pelo leitor, não decifrado. Mas, partindo-se desse pressuposto, mesmo que a análise se torne mais difícil, nós nos empenhamos em apresentar uma leitura daquilo que o texto oferece sobre as questões do gênero: reflexões, esboços...

Há discursos em "Eu e Jimmy" que nos exigiram mais atenção, que nos fizeram debruçar sobre eles, deslindá-los, sem sequer demitir essa função, na verdade, eles chegaram até nós nos despojando algo que, em nós, era extremamente vulnerável e nos requisitando uma resposta consciente, mas talvez sempre insatisfatória. O feminino marcado, a genderificação da criança no interior dos dinamismos familiares, o binarismo problemático e a contingência do gênero foram os fios, os rizomas que fomos traçando na leitura do conto, sem fundo, sem raiz central, espectros que se foram construindo pela (i)materialidade textual, aquilo que está dito e não dito no texto, a voz que nos leva a todo momento às lembranças, à "cabeça" de Jimmy.

Rejeitamos um centro e estabelecemos conexões entre os rizomas do texto e os dos estudos de gênero, sem uma unidade inaugural, nos esforçando para entender, na perspectiva de Deleuze e Guattari (1995), que cada ponto se liga ao outro e ele deve sê-lo, que a linguagem não se fecha estruturalmente em si mesma, que ela se produz de forma intertextual com outros registros. Dessas conexões, podemos responder às demandas discursivas, dizendo que o gênero se insere não numa substância, numa essência, mas num regime do poder, que produz performativamente os corpos dentro de um marco binário e oposicional.

Essa produção do sujeito pôde ser notada através da família, dispositivo institucional que é descrito pela narradora, seu pai, sua mãe, produzindo-a, moldando-a, fazendo-a seguir as ideias do namorado porque, em sua constituição discursiva, algo que lhe parecia intrínseco ao próprio corpo, ela havia aprendido que as ideias dos homens são soberanas em todos os sentidos. Também pôde ser percebida através 
das dicotomias do pensamento ocidental que fazem parte da própria constituição dos personagens, colocando-os em posições bastante específicas: a protagonista reduzida à matéria, a significação lateral ao feminino, e Jimmy, à mente, correspondente ao masculino. Além disso, pela fidelidade exigida da namorada e o espanto de Jimmy ao descobrir que fora traído, sendo que ele mesmo trabalhara a matéria de forma a distanciá-la das condutas morais.

$\mathrm{Na}$ verdade, depois do trabalho que se seguiu aqui, parece bastante evidente dizer que "Eu e Jimmy" nos oferece não só a voz do feminino marcado, aquela voz silenciada na nossa sociedade masculinista, o discurso do Outro, uma matéria cara em meio aos escritos não muito conhecidos de Clarice Lispector, mas também a própria inversão representativa da contingência de gênero, a subversão do poder. Como um escrito da juventude da escritora, o texto aponta maturidade na percepção das relações de gênero, do lugar não legitimado do feminino transgressor na sociedade patriarcal, marcada por valores androcêntricos.

Aqui, foi plenamente justificável ressaltar essa escritura como a própria inversão da desconstrução e o deslocamento da desconstrução, conceitos de Derrida (2001). A inversão, porque se apresenta nos discursos que estão sob o signo desde um "eu" excluído, um outro, recalcado pela marca da voz masculina soberana, marginal, posições que nos levam ao terreno baixo da oposição masculino/feminino e o deslocamento porque os movimentos discursivos do feminino no interior do conto estão além das dicotomias, da hierarquia violenta, colocando-as em juízo de tela, suturando as estruturas rígidas do poder e oferecendo um regime discursivo que não pode ser pensado dentro da lógica determinística do regime anterior.

Enfim, ainda há o texto e ainda há as questões de gênero: esses rizomas, fios de malha e seus princípios. Mas, depois da leitura crítica do texto clariciano, por meio dos estudos de gênero, podemos assegurar que estes movimentos ajudam a deslocar e ampliar o questionamento da ideia de um sujeito uno, centrado e universal, indicando a problematização do sujeito-mulher de forma a considerar como uma determinada composição desse sujeito repercute nos modos de se produzir discursivamente a diferença sexual como traço identitário primordial. 
The feminism voice featured in "Eu e Jimmy”, by Clarice Lispector: REFLECTIONS ON GENDER AND POWER

\section{AbSTRACT}

This present article analyses the conflicts marked by gender asymmetry in the story "Eu e Jimmy" written by Clarice Lispector. To draw some reflections about the (i)materiality of the text, the said and unsaid, the discourses that run and move within the tale, as regards gender relations, we start from the binary mark and oppositional male/female and as well as a family experience of a woman who watched, since childhood, her mother following the ideas of an imperious and serious father, being this woman herself, once learned male supremacy, a follower of the ideas of boyfriends and men in general.

KeY wORDS: Clarice Lispector, gender relations, male supremacy.

La voz de lo femenino marcado en "Eu e Jimmy”, de Clarice

LISPECTOR: REFLEXIONES SOBRE GÉNERO Y PODER

\section{RESUMEN}

Este artículo analiza los conflictos marcados por la asimetría de género en el cuento "Eu e Jimmy" de Clarice Lispector. Para trazar algunas reflexiones sobre la (in)materialidad del texto, lo dicho y lo no dicho y los discursos que parten y circulan en el cuento, en lo que se refiere a las relaciones de género, partimos del marco binario y oposicional masculino/ femenino y de la experiencia familiar de una mujer que vio desde pequeña a su madre siguiendo las ideas del padre rigoroso e impositivo. Habiendo aprendido la supremacía masculina, esa mujer se hizo seguidora ciega de las ideas de sus novios y de los hombres en general.

PALABRAs ClaVE: Clarice Lispector, relaciones de género, supremacía masculina.

\section{NOTAS}

1 O conto "Eu e Jimmy" inicialmente foi publicado na Folha de Minas, em 1944.

2 O texto de fruição é um conceito barthesiano (BARTHES, 2002) para designar aqueles textos que, de alguma forma, rompem em nós, leitores, nossas bases históricas, culturais e psicológicas, nos deslocam de nossa zona de conforto, nos desconfortam sem que possamos nos desviar desses estados. 
3 A "Manifestação para todos" (Manif pour tous) foi realizada no dia 13 de janeiro de 2013, em Paris. Cerca de um milhão de pessoas protestou contra o projeto de governo de François Hollande que pretendia legitimar o casamento gay e liberar a adoção de crianças para casais do mesmo sexo.

4 Marx e Engels (1998) afirmam que "os pensamentos da classe dominante são também, em todas as épocas, os pensamentos dominantes; em outras palavras, a classe que é o poder material dominante numa determinada sociedade é também o poder espiritual dominante. A classe que dispõe dos meios da produção material dispõe também dos meios da produção intelectual, de tal modo que o pensamento daqueles aos quais são negados os meios de produção intelectual está submetido também à classe dominante" (p. 48).

\section{REFERÊNCIAS}

Barthes, Roland. O rumor da língua. São Paulo: Brasiliense, 1988. . O prazer do texto. 3. ed. São Paulo: Perspectiva, 2002.

Beauvorr, Simone de. O segundo sexo: fatos e mitos. v. 1. Rio de Janeiro: Nova Fronteira, 1980a.

Fronteira, $1980 \mathrm{~b}$.

. O segundo sexo: a experiência vivida. v. 2. Rio de Janeiro: Nova

Bonnici, Thomas. Teorias pós-estruturalistas. In: Bonnici, Thomas; Zolin, Lúcia Osana (Orgs.). Teoria literária: abordagens históricas e tendências contemporâneas. 2. ed. Maringá: EDUEM, 2003. p. 145-150.

Bourdieu, Pierre. A dominação masculina. 9. ed. Rio de Janeiro: Bertrand Brasil, 2010.

Butler, Judith. Cuerpos que importan: sobre los límites materiales y discursivos del "sexo". 2. ed. Buenos Aires: Paidós, 2008 a.

.Problemas de gênero: feminismo e subversão da identidade. 2. ed. Rio de Janeiro: Civilização Brasileira, 2008b.

. Performatividad, precariedad y políticas sexuales. Revista de Antropología Iberoamericana. Madrid, v. 4, n. 3, set./dez. p. 321-336, 2009.

DAVIS, R. C. Aristotle, ginecology, and the body sick with desire. In: LeFKOVITZ, L. H. (Ed.). Textual bodies: changing boundaries of literary representation. New York: State University of New York Press, 1997.

Deleuze, Gilles; Guattari, Félix. Mil platôs: capitalismo e esquizofrenia. v. 1. São Paulo: Editora 34, 1995. 
DerridA, Jacques. Posições. Belo Horizonte: Autêntica, 2001.

Foucault, Michel. História da sexualidade I: a vontade de saber. 13. ed. Rio de Janeiro: Edições Graal, 1999.

Grosz, Elizabeth. Corpos reconfigurados. Cadernos Pagu. Campinas, SP, n. 14, p. 45-86, 2000.

Hall, Stuart. Quem precisa de identidade? In: SiLva, Tomaz Tadeu da (Org.). Identidade e diferença: a perspectiva dos estudos culturais. 10. ed. Petrópolis, Rio de Janeiro: Vozes, 2011.

Lauretis, Teresa de. A tecnologia do gênero. In: Hollanda, Heloisa Buarque de. Tendências e impasses: o feminismo como crítica da cultura. Rio de Janeiro: Rocco, 1994. p. 206-242.

Lispector, Clarice. Eu e Jimmy. In: Montero, Teresa; Manzo, Lícia (Orgs.). Outros escritos. Rio de Janeiro: Rocco, 2005. p. 16-19.

Marx, Karl; Engels, Friedrich. A ideologia alemã. São Paulo: Martins Fontes, 1998.

MotTA, Alda Brito de. Teoria das gerações na perspectiva de gênero. In: CRUz, Maria Helena Santana; Alves, Amy Adelina C. de Faria (Orgs.). Feminismo, desenvolvimento e direitos humanos: multiplicidade de questões feministas. Aracaju: REDOR/NEPIMG/UFS/FAP-SE, 2005. p. 131-137.

Preciado, Beatriz. Qui défend l'enfant queer? Liberátion. 2013. Disponível em: <http://www.liberation.fr/societe/2013/01/14/qui-defend-l-enfant-queer_ 873947>. Acesso em: $1^{\circ}$ jan. 2013.

Santiago, Silviano. (Superv.). Glossário de Derrida. Rio de Janeiro: Francisco Alves, 1976.

SARTI, Cynthia A. Reciprocidade e hierarquia: relações de gênero na periferia de São Paulo. São Paulo, Cad. Pesq.[on-line], n. 70, ago. p. 38-46, 1989. Disponível em: $<$ http://educa.fcc.org.br/scielo.php?pid=S0100157419890003 00004\&script $=$ sci_abstract $>$. Acesso em: 10 fev. 2013.

Wittig, Monique. El pensamiento heterossexual y otros ensayos. Madrid: Egales, 2006.

Recebido em 31 de março de 2013

Aprovado em 22 de outubro de 2013 